\title{
Subtitle Translation of Foreign Movies and TV Series under Skopos Theory*
}

\author{
Liangqiu Lv \\ North China Electric Power University, Beijing, China \\ Hongye Zhu \\ North China Electric Power University, Beijing, China \\ Puyu Ning \\ North China Electric Power University, Beijing, China
}

\begin{abstract}
The wide spread of foreign movies and TV series has brought upon the heat of the subtitle translation. This paper describes different subtitle translation principles and styles under the skopos theory using the example of English-Chinese translation. While purpose principle plays the main decisive role in the translation process as the primary principle, loyalty and consistency principle should be observed in the translation process as well. Besides, translators tend to apply different translation styles when they handle different types of movies, which is determined by the degree of adequacy, the reception of target audience under the skopos theory.
\end{abstract}

Index Terms - translation, skopos theory, subtitle, foreign movies and TV series

\section{INTRODUCTION}

In recent years, Chinese audience have greatly changed their taste in foreign movies appreciation as to how they're presented, which is shown through their preference nowadays to original sound of the movie instead of the dubbed one. (Zhang, 1998, p.50-53) As a result, the subtitle translation is of even greater importance than ever. Excellent subtitle can not only bring the truest language features to Chinese audience, which can also help them learn a bit of foreign language, but also it can bring the audience closer to foreign cultural circumstances, making them feel less distanced.

As a matter of fact, subtitle fan clubs are now pervasive on the internet in China, especially those set up for popular American movies and TV series. They are absolutely helpful to Chinese audience, despite the fact that they are made up with voluntary movie enthusiasts, who offer to make subtitles out of nothing more than their fancy for foreign television work. Thanks to them, Chinese audience can enjoy more of the original TV series from overseas, and intercultural communications are moving to a whole new level.

The Greek word "skopos" is a technique term for the goal or purpose of a translation. So it's pretty much safe to say that skopos theory employed in translation means the purpose of the translation action determines the target text. This paper aims to analyze subtitle translation based on this theory, which helps in enhance the quality of translation on account of different types of TV work. (The English-Chinese subtitles mentioned below are all from YYeTs Group over the Internet.)

\section{MAIN VIEWPOINTS IN SKOPOS THEORY}

The skopos theory was developed in Germany in the late 1970s. Since it reflects a general shift from linguistic and formal translation theories to a more functionally and socio-culturally oriented concept of translation, it has become "a welcome addition to translation studies" (Gentzler, 2001, p.71). Initially formulated by Reiss in the 1970s, the theory was enunciated by Vermeer in the 1980s, and was further developed in the 1990s by Nord, one of its most important second-generation scholars. Vermeer's theoretical framework of skopos will be applied to explain the role that the purpose plays in the process of translation in the followings.

Hans Vermeer argued that translation is a purposeful action of consequence based on the original text, which should be accomplished through negotiation and determined by the purpose of translation. He thought that the highest principle in the process of translation should be "the skopos rule", and he also put forward the concept of translation commission, which means that translators got to decide whether, when and how to do the translation job. (Ma \& Miao, 2009)

In Vermeer's skopos theoretical framework, one of the most important factors that influenced translation purpose is the target audiences, who have got their own cultural backgrounds, translation expectations and communicative needs. Later, Christiane Nord combed through all the functionalist school theories and further perfected the theory by putting

\footnotetext{
${ }^{*}$ The present paper is supported by the Fundamental Research Funds for the Central Universities of China.
} 
forward her own functional model, i.e. functionality plus loyalty, which means apart from conforming to the requirements of the translation skopos, the translator should also respect the legitimate interests of both the author of the original and the readers of the translation. Therefore, translators should bear in mind what the function of translation text is, what the target readers' demand is and even what communicative situation is. Consequently, the choice of translation strategies is decided by the purpose of the translation text, in order to achieve a better functioning text.

Under skopos, the Chinese subtitles for foreign TV work can be seen as specific Chinese discourse aiming at the total comprehension and understanding of alien culture for Chinese audience. While the show's type varies, the translators tend to reach different goals, thus having multiple translation strategies. For instance, The Big Bang Theory, 2 Broken Girls, How I Met Your Mother, namely the American TV comedies popular here in China, attract mostly young audience groups with their goal of being hilarious and entertaining. Consequently, the translation of corresponding subtitles is mainly referring to the most "in" words at present, making the audience feel the humor and relaxation while watching the show. On the other hand, for western history dramas, like Tudors, Camelot, Downton Abbey, historical accuracy surely comes before oral humor concerning the subtitle translation.

\section{TRANSLATION PRINCIPLES UNDER SKOPOS THEORY}

The top-ranking rule for any translation is thus the skopos rule, which means that a translation action is determined by its skopos, which means "the end justifies the means" put forward by Reiss and Vermeer. Vermeer (Vermeer, 1989, p.112) also stresses on many occasions that the skopos rule is a general rule, and translation strategies and methods are determined by the purpose and the intended function of the target text. Apart from the primary purpose rule, there are also coherence \& fidelity and loyalty rules under the skopos theoretical framework.

Generally speaking, "purpose" refers to the communicative purpose of the target text, which is the communicative function the target text imposes to the target audience in the target environment. As a result, translators get to define their specific purpose in the given translation context, and decide the translation method, including literal translation, free translation and the one caught in between in accordance with the purpose. So it is totally understandable for translators to try different translation approaches when it comes to different types of TV series to achieve their particular goal. Naturally, comedies want to make audience laugh while horror movies want them scared out of wits. To accomplish such "ideal" effects, translators are doing their best to make the target audience feel the same way the foreign audiences do. Here are the examples from The Big Bang Theory.

In the Fourth Episode from Season Three, Sheldon thought that when Penny called him sweetie, she didn't actually mean it by intimacy but euphemistic sarcasm. However, sometimes, she meant it without trying to hide it at all.

Although, sometimes, she omits the veil entirely

但有时候她就是赤裸裸的讽刺。

Here, the translator used free translation, rendering “omit the veil” as “赤裸裸的讽刺”, which means blank and utter sarcasm, showing the implied meaning by Penny in a funny way. The Chinese adjective “赤裸裸的” here means the most obvious presentation of the sarcastic sensation. It also appeals to the mentality of Chinese audience since the euphemism has been exposed in such an ironic way.

Also in this episode, Raj was depressed and anxious about his about-to-be-cancelled visa, so he was rather anxious when he said:

--“Sorry, I lost my cool."

--“对不起, 我失态了。”

The phrase “lost my cool” was a colloquial expression, which means “我失了冷静” if translated literally. But the translator used “我失态了” instead, more conforming to the Chinese speaking habit, also making the Chinese audience feel hilarious.

Later in this episode when Sheldon and Raj were working on solving a scientific problem together, they couldn't find the solution even though they have been racking their brains for days and nights. Raj said: "I need an aspirin", which is translated into “我需要一片脑残片”. The original meaning of “aspirin” is a pain-killer while the newly-coined Chinese word “脑残片” means “cure for doofus". So the translated subtitle shows the baffled and challenged image of Raj to target audience like a comedian. And based on the reception degree of Chinese audience, they are practically laughing their tears out when they see the subtitle.

Coherence rule means that the translation must observe the standard of intra-textual coherence, which would make the translated text readable and acceptable for target audience in an actual communicative context. It states that the target text must be interpretable as coherent with the target text in receiver's situation. In other words, the target text must be translated in such a way that it is coherent for the target text receivers given their circumstances and knowledge. In terms of coherence rule, the source text is no longer of most authority but only part of the translation belief. It is only an offer of information for the translator, who in turn picks out what he considers to be meaningful in the receiver's situation.

Meanwhile, fidelity rule states that inter-textual coherence should be complied between the original and target text, which requires the translator to be loyal to the original text and also produce a text at the same time. The degree of faithfulness depends on the purpose of the target text and the translators' understanding of the source text. Applying this 
rule in translation, the translated subtitles should not only express the intended meaning, but also convey the most coded implications in a fluent and accurate way. Since the majority of the words in TV shows are dialogues, translators are required to use brief and concise words to render the conversations or narrations from the video. In the movie Letter to Juliet, the heroine Sophie is a truth investigator and she has been looking for a witness, who saw the classic picture Victory Kiss in Time Square back in 1940s. She asked:

--“The kiss was it spontaneous or was it staged?"

--“那个吻, 是情不自禁, 还是事先安排的? ”

The translator used free translation paraphrasing the word “spontaneous” as “情不自禁”, which means “improvised, can't help oneself", communicating the heartfelt emotion burst from the soldier, who's just got back from the battlefield in World War II. Naturally and for grant, they were caught in the moment and kissed right in the middle of Time Squire, where was filled with happy and exciting crowds celebrating the great victory. The word “情不自禁” just happens to bring back all that commotion and crazed atmosphere in the front of all the audience, which is both loyal to the original line and also contrary to the concept of "staged" as well.

This rule was prompted by Nord, who discovered the shortcomings of skopos. She found out the problems caused by radical functionalism, namely, a translation purpose as specified by the translation brief is at variance with the original author's intentions. So she put forward the "functionality plus loyalty" model, fixing the deficiency of skopos theory by coordinating the intentions of the original author and translator. Also in the movie Letter to Juliet, Sophie visited the former residence of Juliet (Casa dl Guilietta) in Verona, where she met the "secretaries" of Juliet who have been responsible for responding letters to those wrote to Juliet. One of the secretaries is an old lady, who has been married to her husband for over 51 years, as a result of which she has been covering various letters complaining about marriage. She said:

--“Husbands are like wine. They took a long time to mature."

--“丈夫就像是红酒, 需要久酿才能使之香醇。”

The translation of simile here is quite literal, loyal to the original line, mostly because there is similar usage of the word "mature" in English countries and China. The word "mature" has two levels of meaning, one being the fermentation of wine, the other being the growing of personality of men, while in this circumstance, the husbands. Apart from the universal usage of words, there is shared mentality here by female audience, which is the desired effect of a functional translation, while at the same time, reserving the exact meaning of the original expression.

\section{TRANSLATION APPROACHES TO MOVIES AND TV SERIES}

As we all know, different types of movies and TV series intend for the audience to have different feelings with various information. So under skopos, translators usually apply different styles when it comes to different kinds of movies or different personalities of characters from the movies. The following part lists three types of movies or TV series and introduces respectively their corresponding translation approach.

As the increasingly deepened communication between cultures, foreign history drama has also become quite popular in China, like Troy, Brave Heart, Tudors and Camelot. Downton Abbey is also a popular British period drama at present. The series, set in the Yorkshire county estate of Downton Abbey, depicts the lives of the aristocratic Crawley family and their servants in the post-Edwardian era-with the great events in history having an effect on their lives and on the British social hierarchy. The following dialogue is taken from the first episode of season two, Lord Grantham said:

--“Churchill went back to the front after the Gallipoli business. If he could, why shouldn't I?"

--“加利波利战役后丘吉尔不也返回前线了，如果他都可以，凭什么我不能？”

[加利波利战役: 一战中, 英军伤亡惨重的一场战役]

Besides the translation of his words, the translator also added comment statement after the translation, explaining the Gallipoli battle so that the Chinese audience know the reason why Lord Grantham compared himself to Churchill. To translate period drama like Downton Abbey, it is quite essential for the translators to pay absolute attention to the accuracy in terms of historic details, which can also instill some information to Chinese audiences.

Also in this episode, the footman William asked:

--"What is it?"

--“A white feather, of course. Coward."

--“这是什么?”

--“当然是白羽毛了。懦夫。”[一战前, “白羽会”在英国成立, 其成员向平民分发象征懦弱的白羽, 敦促公民 参军。]

The additional remarks here also help popularize some history common sense among Chinese audience, accounting for the insinuation of "white feather", which shows the irony of the fund-raising concert. People sitting in the concert would rather talk and socialize than go to the battlefield fighting for their own country.

Romantic stories are always popular among audiences whether they are domestic or foreign. The well-known Jane Eyre is one of the most popular stories in China. Adapted from Bronte's novel of the same name, Jane Eyre has been made into different versions of movies and TV series. Translators are keen on making the translated subtitle equally literary and aesthetic. Here's the dialogue from the movie Jane Eyre made in 2011. Rochester said to Jane: 
"But you might suit, by distracting me from the mire of my thoughts."

“把我从我思绪的泥潭中拽出来。”

Rochester said that Jane could save him from the myriad of thoughts. The translator here used literal translation, reflecting the troubled status of Rochester by rendering the word “拽” and “泥潭”, which is a perfectly vivid combination of phrases. It conveys the motion of salvation Jane offers to Rochester. Despite the different expression from the original line, the translated line does a good job of delivering the right spirit.

Later in their conversation, Rochester found that Jane was very nervous with a stiff face, so he said:

--“But you are not naturally austere, any more than I'm naturally vicious."

--“但你并非生来就如此严肃, 就像我并非天生就是个恶棍。”

The adjective “vicious" is translated into a noun “恶棍”, which means a villain, or a bad guy, instead of literal translation complying with the language habit of Chinese. In this way, it shows the self-mockery of Rochester for his aggression. Also, the expression helps build the image of Rochester as a tough-looking man with poison words.

There's no doubt that the comedy is the most loved and popular TV series among youngsters, especially the sitcoms. The following part describes the funny style of translation taking the example of Sheldon's words from The Big Bang Theory. After all, his words have always been the highlight of the whole show.

Please reserve that butch spirit for the lanes.

请把这纯爷们儿的气场发挥在赛场上吧。

Here, from Sheldon's point of view, Penny is a “纯爷们儿”, which is a network hot word in China meaning a real macho man unlike the sissies, who can help him win the bowling match. Obviously, we have to admit compared to the indoors nerds like Leonard and Sheldon, Penny does stand out looking like a bigger shot at the bowling game.

This has to be the worst day of my life.

今天真是我一生中最扯淡的一天。

In the sentence, “the worst” is translated into “扯淡”. Only the Chinese audience can taste the hilarity of the word “扯淡” in the context, especially when it's used to translate Sheldon's words because he is apparently the mocking type who can bitch about almost everything.

The only flaw in the otherwise perfect plan

智者千虑, 必有一失

It's quite a convincing idiom in Chinese and it perfectly expresses the exact meaning of the original sentence. Also, it shows Sheldon's overrated confidence about his competence.

Conclusive proof that I'm absolutely worthless after 9 o'clock

事实证明, 我九点过后就是一条废柴。

The translator used the word “废柴” to render Sheldon's self-joking about being completely incompetent when working late hours, which is also a classic example of combination of Chinese buzzword and Sheldonian ridicule.

Looks like the rumpled chicken's come home to roost

看来现在有人要自食恶果了吧。

The one thing about Sheldon, which would drive anyone into insanity, is that although you would hate to admit it, he is always right. The English adage “rumbled chicken come home to roost” is translated into a Chinese idiom “自食恶 果”, which seems appropriate and acceptable rendering the audience to laugh about Sheldon's mocking object.

One thing about Sheldon, which would make you laugh, is that he doesn't know or care what other people might think of him. Despite the fact that he often carelessly makes others hit the ceiling, he thinks of himself as a "delight". To achieve that effect, the subtitles for his lines focus on such contrast by means of ironic exaggeration. In one episode, Sheldon commented himself as a “delight”, which is translated into “我超萌超可爱的”. Chinese audience could hardly resist bursting into laughs because “萌” and “可爱” seem to be the last words Alex would use to describe Sheldon.

Certainly, besides Sheldon, other stars from the show also help bring the laughing element to the audience, especially the female roles. Penny, for instance, is really good at making her boyfriend Leonard's nerd nature stick. Here is her proof when Leonard got a paper cut.

Of course you did. Your hands are softer than veal.

完全不意外, 你的芉芉玉手比小牛肉还嫩呢。

For comments like “芉芉玉手”, there is one thing you should be certain about, which is that they are for young, well-protected girls to describe their beautiful and well-shaped soft hands. So you can totally understand Penny's mocking. Later in the show, when Penny found out that Sheldon's assistant Alex hit on Leonard and he actually loved such admiration from other women. And when she confronted Leonard and he wouldn't admit it, she broke out and said:

--“Don't play dumb with me, Ricardo Shilly-Shally."

--“别跟老娘装俊, 里卡多·谢利沙力。”

Although the word “老娘” is a little bit rude Chinese slang, it does show that she is really pissed after she found out Leonard is also a discontented man, who is not satisfied with her being his girlfriend, instead, like all other men, enjoying all kinds of female attention. Chinese viewers, especially female audience could really have the same 
sympathetic reaction here. And the vulgar word “老娘” nowadays is also used by many Chinese girls to refer to themselves, particularly when they are angry and upset.

Also in this episode, Penny, Bernadette and Amy are helping Raj find girls who might be interested in him in a club, and they found a girl who just got dumped by her boyfriend, and her favorite movie was Slum Dog Millionaire. So Amy said:

--“That is some low-hanging fruit."

--“必须手到擒来啊。”

The expression "low-hanging fruit" is intended to describe how easy it should be for Raj to pick up that girl, while the Chinese idiom “手到擒来” vividly paints the picture. Unfortunately, Raj failed to pick the fruit even though it's already hanging pretty low. So the "hard truth" helps make the expression create a funny yet sad environment around Raj.

\section{CONCLUSION}

The translation rules in skopos theory play an instructive role in the guidance of subtitle translation with different rules targeting varied types of movies and TV shows. With the target audience's language habit being their priority concern, the subtitle fan club does a better job of attracting more viewers of the foreign drama. Despite that the subtitle fan club can only represent one school of opinion, their work has undoubtedly brought great convenience for Chinese audience, which not only let audiences learn about foreign culture visually, but also build a communication bridge between Chinese audience and foreign viewers.

The practice of skopos theory has been proved effective as to the reception of translated subtitles among Chinese viewers, which can be seen from the prevalent foreign TV series and the ever-increasing fan groups. This paper only gives a brief introduction of the subtitle translation practice here in China, in a broader sense, which can only represent a relatively small part of the inter-cultural communication process. And hopefully, the popularity of those fan clubs can go better and further way in the cause. As far as it goes, it serves the goal of synchronizing the viewing experience between foreign and home audience, which in a way, helps bring people around the world closer and enhance the sense of approval.

\section{REFERENCES}

[1] Gentzler, Edwin. (2001). Contemporary Translation Theories. London \& New York: Routledge.

[2] Liu, M. (2008). Subtitle Translation of Foreign Movies. Xiamen: 2008 Conference Proceedings of Fujian Literary Guild.

[3] Ma, H. \& Miao, J. (2009). Selected Readings of Contemporary Western Translation Theories. Beijing: Foreign Language Teaching and Research Press.

[4] Venuti, Lawrence. (2000). The Translation Studies Reader. London \& New York: Routledge.

[5] Vermeer, H. J. (1989). Skopos and Commission in Translational Action. (Chesterman, A. Trans.). In Chesterman, A. (Ed.), Readings in Translation Theory. Finland: Oy Finn Lectura Ab.

[6] Zhang, C. (1998). Brief Discussion of Movie translation. Chinese Translators Journal, 2, 50-53.

Liangqiu Lv was born in Anhui, China in 1973. He received his Master's degree from University of Science and Technology Beijing, China in 2004.

He is currently an associate professor in the School of Foreign Languages, North China Electric Power University, Beijing, China. His research field is theory and practice in translation.

Hongye Zhu was born in Zhenjiang, China in 1990.

She is currently a Master candidate in the School of Foreign Languages, North China Electric Power University, Beijing, China.

Puyu Ning was born in Tianjin, China in 1977. She received her Master's degree from North China Electric Power University, Beijing, China in 2007.

She is currently a lecturer in the School of Foreign Languages, North China Electric Power University, Beijing, China. Her research field is theory and practice in translation. 